\title{
Formação inicial e continuada de professores que ensinam Matemática na escolarização inicial
}

\author{
Initial and continuing education of teachers who teach Mathematics in initial schooling
}

Rute Elizabete de Souza Rosa Borba ${ }^{1}$

\begin{abstract}
Resumo
Nesse texto são discutidas as cinco dissertações de mestrado identificadas das áreas de Ensino e de Educação, concluídas no período de 2008 a 2012, que tratam tanto da formação inicial quanto da formação continuada de professores que ensinam Matemática nos anos iniciais de escolarização. Em três dissertações discutiu-se a colaboração entre pesquisadores de instituições de ensino superior (IES) e professores da Educação Básica. Um dos estudos discutiu a articulação entre a formação em Pedagogia e a prática de ensino de Matemática, e um outro estudo teve a tecnologia na formação de professores como foco. Constatou-se que um bom caminho para a articulação entre a formação inicial e a formação continuada são processos que incentivem a cooperação entre diferentes profissionais de fora e de dentro da escola, incluindo-se aí pesquisadores de IES e os professores dos distintos níveis de ensino da escola, de modo que todos se sintam corresponsáveis pelo desenvolvimento matemático dos alunos.
\end{abstract}

Palavras-chave: Articulação formação inicial-formação continuada; professor que ensina Matemática; anos iniciais do Ensino Fundamental.

\begin{abstract}
This paper discusses five master's dissertations identified from the areas of Teaching and Education, concluded between 2008 and 2012, which deal with both the initial and the continuing education of teachers who teach Mathematics in the initial years of schooling. Three of the dissertations discussed the collaboration between university researchers and teachers of Basic Education. One of the studies discussed the articulation between Pedagogy education and the teaching practice of Mathematics, and another study investigated the use of technology in teacher education. It was found that a good way to articulate initial and continuing education are processes that encourage cooperation between the different professionals from in and out of the school, including university researchers and the teachers of the distinct levels of education within the school, so that they all feel co-responsible for the mathematical development of the students.
\end{abstract}

Keywords: Articulation initial-continuing education; teacher who teaches Mathematics; Elementary School.

\section{Introdução}

O presente texto tem como objetivo discutir pesquisas que se referem tanto à formação inicial quanto à formação continuada de professores que ensinam Matemática nos

\footnotetext{
${ }^{1}$ Doutora em Educação Matemática pela Oxford Brookes University, Reino.Unido. Professora da Universidade Federal de Pernambuco. Email: resrborba@gmail,com
}

Zetetiké, Campinas, SP, v.25, n1, jan./abr.2017, p.94-134 
anos iniciais da Educação Básica, ou seja, graduandos em Pedagogia ${ }^{2}$ e professores que atuam na Educação Infantil e/ou no $1^{\circ}$ ao $5^{\circ}$ ano do Ensino Fundamental. Nesse sentido, foram analisadas dissertações brasileiras de programas de pós-graduação stricto sensu, caracterizadas pela Coordenação de Aperfeiçoamento de Pessoal de Nível Superior (Capes) como áreas de Ensino e de Educação, que versam sobre formação inicial e continuada de professores que ensinam Matemática no início da escolarização.

Trata-se de subprojeto de um levantamento realizado no estudo "Mapeamento e estado da arte da pesquisa brasileira sobre o professor que ensina Matemática" ${ }^{3}$. Este foi um projeto elaborado pelo Grupo de Estudo e Pesquisa em Formação de Professores de Matemática (GEPFPM) e desenvolvido por pesquisadores de variadas Instituições de Ensino Superior das diversas regiões do Brasil. O objetivo principal desse projeto maior foi o de mapear, descrever e sistematizar as pesquisas brasileiras produzidas no âmbito dos programas de Pós-Graduação, no período de 2001 a 2012, que têm como foco de estudo o professor que ensina Matemática (PEM).

Embora o projeto maior tenha um foco mais amplo, o presente subprojeto visa analisar a produção referente à formação do PEM que atua nos anos iniciais da Educação Básica e, especificamente, busca discutir estudos que tratam ao mesmo tempo da formação inicial e da continuada ${ }^{4}$. Outras temáticas relativas ao professor que ensina Matemática - tais como saberes e competências; atitudes, crenças e concepções; identidade e profissionalidade; características e condições do trabalho docente; desempenho docente; história de professores; atuação, pensamento ou saberes do formador de professores - embora tratadas de alguma forma, não foram foco direto do presente recorte.

Em levantamento anterior, André (2009) realizou estudo comparativo das dissertações e teses da área de Educação defendidas nos anos de 1990 e 2000 que trataram da formação de professores, e observou um crescente interesse pelo tema. Nos anos 1990, 6\% dos estudos em Educação abordavam a formação de professores, percentual que cresceu para $14 \%$ nos anos 2000. Das 6.244 dissertações e teses, de 1990 a 1998, 410 trataram da formação do professor. Nos cinco anos seguintes, a produção total da área de Educação passou para 8.280 trabalhos, dos quais 1.184 abordaram o tema. Entretanto, desse total, apenas 3\% trataram simultaneamente a formação inicial e a continuada de professores.

\footnotetext{
${ }^{2}$ As pesquisas aqui discutidas não tratam de professores formados somente em Escola Normal, uma modalidade de formação, em curso de Ensino Médio, de alguns professores da Educação Básica.

3 Projeto submetido e aprovado pelo CNPq (Projeto Universal - 486505/2013-8), resultando no e-book localizado em https://www.fe.unicamp.br/pf-fe/pf/subportais/biblioteca/fev-2017/e-book-mapeamento-pesquisapem.pdf

${ }^{4}$ Dois outros levantamentos fazem parte deste mesmo subprojeto: um que se refere exclusivamente à formação inicial, e outro que se refere exclusivamente à formação continuada de professores que ensinam Matemática nos anos iniciais do Ensino Fundamental. Texto sobre o primeiro foco foi desenvolvido por Ana Abrahão (UNIRIO) e Sandra Fraga da Silva (IFES), e texto sobre o segundo foco foi desenvolvido por Maria Auxiliadora Megid (PUCCAMP) e Rosana Lima (UNICAMP).
} 
Além de ressaltar que pesquisas com foco nessas duas dimensões de formação inicial e continuada - não são muito frequentes, André (2009) também destacou que foi marcante o crescimento de pesquisas que trataram de novas tecnologias e de educação matemática, e apontou como prováveis temas emergentes: formação de professores de cursos superiores, i.e. formação de formadores, condições de trabalho, principalmente questões sobre a saúde dos docentes; o uso de tecnologias educacionais e a educação a distância na formação de professores. Comentou, também, em suas considerações finais, que é preciso cuidado para não reforçar a ideia de que cabe ao professor toda a responsabilidade pelo sucesso ou fracasso da educação, pois outros fatores, tais como condições de trabalho, gestão escolar e políticas educacionais, também precisam ser levados em consideração.

O estudo aqui relatado trata especificamente de pesquisas, voltadas à formação inicial e continuada, desenvolvidas junto a professores que ensinam Matemática nos anos iniciais da Educação Básica. No estudo, descreve-se e discute-se os objetivos, contextos de pesquisa e principais resultados dos trabalhos analisados. Para alcançar o objetivo proposto, inicialmente se discute pressupostos teóricos referentes à formação inicial articulada à formação continuada, e, em seguida, caracteriza-se e analisa-se os principais aspectos dos dados levantados.

\section{Pressupostos teóricos sobre a formação inicial articulada à formação continuada de professores}

Segundo o Dicionário Michaelis, um dos significados de formar é desenvolver ${ }^{5}$. Desse modo, professores - como outros profissionais - estão em contínua formação, ou seja, em contínuo desenvolvimento. A formação inicial em cursos de graduação e em outras atividades extracurriculares desempenha um importante momento de aprendizado docente. No entanto, o exercício do magistério exige uma formação contínua, que pode ser feita por meio de cursos de pós-graduação, em seminários, em congressos científicos, em programas de formação continuada, em estudos teórico-metodológicos individualizados e coletivos, em reuniões pedagógicas da escola, bem como no próprio exercício da prática em sala de aula.

Gatti (2010) ressalta que a preocupação com a formação de professores se faz presente em diversos países, tanto pela necessidade de atualização que o mundo de trabalho atual impõe, quanto pela constatação de precários desempenhos por parte de muitos estudantes. Desse modo, professores precisam continuamente adaptar-se a novas realidades tal como a informatização crescente das sociedades - e preparar-se para ensinar, cada vez melhor, as novas gerações para a cidadania plena.

$\mathrm{Na}$ formação inicial, o futuro professor deve desenvolver conhecimentos de conteúdos e conhecimentos pedagógicos que o habilitem a exercer a docência em toda a sua complexidade. Contudo, o tempo de formação inicial não é suficiente para preparar

\footnotetext{
${ }^{5}$ Disponível em http://michaelis.uol.com.br/busca?r=0\&f=0\&t=0\&palavra=formar. Data de acesso: 07 de abril de 2017.

Zetetiké, Campinas, SP, v.25, n1, jan./abr.2017, p.94-134

ISSN 2176-1744
} 
plenamente nenhum profissional e, em particular, o professor que exerce atividades com diversos enfoques: científico, cognitivo, psicopedagógico, sociológico, dentre outros. Além disso, em alguns cursos a formação referente a conteúdos é desarticulada da formação pedagógica - cabendo ao professor encontrar por si só caminhos de articulação entre seus conhecimentos de conteúdo e pedagógicos (Moreira \& David, 2007), o que faz com que a formação continuada seja indispensável para o constante desenvolvimento do professor.

Entende-se desenvolvimento profissional docente a partir da definição dada pela OECD - Organisation for Economic Co-operation and Development, ou seja, atividades que desenvolvem habilidades, conhecimentos e outras características do professor. $\mathrm{O}$ desenvolvimento profissional tem como objetivos: atualizar conhecimentos à luz de avanços recentes na área; atualizar habilidades, atitudes e abordagens à luz do desenvolvimento de novas técnicas de ensino, novos objetivos, novas circunstâncias e novas pesquisas educacionais; habilitar indivíduos e escolas a aplicarem mudanças ao currículo ou outros aspectos da prática de ensino; trocar informações e experiências entre professores e destes com acadêmicos; e auxiliar professores a serem mais eficientes (OECD, 1998).

Nóvoa (1991) defende que a identidade docente, ou seja, o reconhecimento social da profissão de professor, deve considerar três dimensões: o desenvolvimento pessoal, resultante de processos de construção de vida do professor; o desenvolvimento profissional, relacionado à profissionalização docente; e o desenvolvimento institucional, referente aos investimentos da instituição no alcance da identidade docente. Nessa perspectiva, o desenvolvimento profissional docente baseia-se num continuum de formação, no qual a formação inicial (em cursos de licenciatura, em particular em Pedagogia) é o começo de um processo que ocorrerá ao longo do exercício da carreira, por intermédio de formação continuada.

Segundo o Parecer CNE/CP 009/2001, referente às Diretrizes Curriculares Nacionais para a Formação de Professores da Educação Básica, em nível superior, curso de licenciatura de graduação plena, o desenvolvimento docente requer competências que incluem "cultura geral e profissional; conhecimento sobre crianças, jovens e adultos; conhecimento sobre a dimensão cultural, social e política da educação; conteúdos das áreas de ensino; conhecimento pedagógico; conhecimento advindo da experiência” (BRASIL, 2001, p. 38). Dessa forma, observa-se como a formação inicial se articula com a formação continuada, uma vez que essas competências se desenvolvem nos cursos de graduação e nas experiências vivenciadas em sala de aula.

Sendo a prática de ensino o foco central da formação docente, não se pode dissociar a formação inicial da continuada, uma vez que a prática é o elemento que une os processos formativos docentes (Pimenta, 2012; Tardif, 2014). A prática se apreende em discussões teóricas e em exercícios práticos - vivenciados em momentos de formação inicial e continuada. Daí a indissociabilidade dos distintos períodos de formação docente.

Roldão (2007) constata que têm sido muito poucos os estudos cujo foco esteja nos dois modos de formação - inicial e continuada. A autora ressalta que a não articulação dos 
dois campos de investigação contraria a concepção do desenvolvimento profissional como um continuum (Nóvoa, 1991), ou seja, um processo continuado de crescimento do professor que envolve a formação inicial e a continuada.

Foi pensando na formação permanente do professor, ou seja, formação como continuum constante, que se realizou o levantamento que segue, buscando caracterizar e analisar os estudos que têm foco tanto na formação inicial quanto na continuada de professores que atuam no início da escolarização. São, dessa forma, apresentados os estudos com esse foco duplo e discutidas as suas ênfases, seus resultados e o que nos apontam, referentes à formação de professores que ensinam Matemática nos anos iniciais do Ensino Fundamental.

\section{Características do corpus de estudos analisados}

Das 858 dissertações e teses identificadas no projeto, 135 tratam da formação do professor que ensina Matemática nos anos iniciais da Educação Básica. Esses estudos estão, assim, distribuídos: 59 trabalhos que abordam a formação inicial, 71 que tratam da formação continuada e cinco que discutem a formação inicial e continuada. Ressalta-se que 34, das 858 pesquisas ao todo, focam conjuntamente a formação inicial e continuada, mas dessas apenas cinco (cerca de 15\%) são voltadas aos anos iniciais de escolarização. Assim, em outros níveis de ensino há um interesse maior em pesquisas dessa natureza, e é necessário estimular mais estudos que envolvam tanto profissionais que estejam em formação quanto em atuação nos primeiros anos da Educação Básica.

Observa-se, desse modo, que, nos últimos anos, pesquisas de mestrado e doutorado no Brasil que abordaram conjuntamente a formação inicial e continuada de PEM no início de escolarização são muito poucas. Dentre a totalidade de pesquisas levantadas (858), cerca de $16 \%$ abordam a formação do professor de anos iniciais e, dentre essas, menos de $4 \%$ tratam simultaneamente da formação inicial e continuada. Verifica-se, portanto, que do total de dissertações e teses brasileiras, de 2001 a 2012, que estudaram o PEM, menos de 1\% pesquisaram, conjuntamente, a formação inicial e continuada dos professores de anos iniciais - o que evidencia a mesma tendência encontrada por André (2009), de número bem reduzido de estudos que têm foco nos dois modos de formação.

Esse é um dado que mostra que, até o presente, poucos pesquisadores tiveram interesse em investigar, simultaneamente, professores em formação e professores atuantes nos anos iniciais de escolarização. A investigação conjunta desses processos - de formação inicial e continuada - ainda carece, então, de mais pesquisas, em particular em perspectivas que considerem a formação como um continuum e que, principalmente, valorizem a riqueza de interações entre os professores em formação inicial e os que atuam em sala de aula dos anos iniciais do Ensino Fundamental.

Os cinco estudos do presente levantamento, que tratam simultaneamente da formação 
inicial e continuada de professores que ensinam Matemática no início da escolarização, foram desenvolvidos em três das sete regiões/estados do projeto, do qual o presente estudo é um recorte: região Centro-Oeste, estado de Minas Gerais e estado de São Paulo. Essas pesquisas foram desenvolvidas em distintas Instituições de Ensino Superior: Universidade de Brasília (UnB), Universidade Cruzeiro do Sul (Unicsul), Universidade São Francisco (USF), Pontifícia Universidade Católica de São Paulo (PUC - SP) e Pontifícia Universidade Católica de Minas Gerais (PUC - MG). Pesquisas de outras regiões não foram localizadas, o que indica que investigações de formação inicial em conjunto com a continuada em outras localidades também necessitam ser realizadas e divulgadas, como modo de analisar experiências de formação nas distintas regiões e nos diversos estados brasileiros.

As cinco pesquisas são dissertações, sendo quatro de programas de Ensino e uma de Educação. Quatro das dissertações são de mestrado acadêmico e uma de mestrado profissional. Nenhuma tese brasileira de doutorado, no período de 2001 a 2012, foi desenvolvida com o foco conjunto na formação inicial e continuada do PEM nos anos iniciais.

Acredita-se que teses na temática relativa à formação inicial articulada à formação continuada são bem relevantes, uma vez que permitem discutir, com maior profundidade, pressupostos - que podem ser amparados em levantamentos empíricos - sobre a formação contínua do professor dos anos inicias, em particular referente ao seu preparo em cursos de graduação e sua atuação no ensino da Matemática em sala de aula. Uma tese de doutorado pode, inclusive, abordar de modo longitudinal um grupo de professores em formação inicial e posterior formação continuada. Outra possibilidade de tese seria a de avaliar a sustentabilidade de um programa de desenvolvimento profissional docente (Zehetmeier \& Krainer, 2011), para que se verifique os efeitos duradouros de um programa algum tempo depois de ser implementado. Muitos investimentos são realizados, e torna-se necessário averiguar efeitos de longo prazo de formações docentes - o que pode ser viabilizado em uma tese de doutorado.

As investigações descritas no presente artigo foram finalizadas no período de 2008 a 2012, curiosamente uma dissertação por ano. Não coincidentemente, nessa época surgiram muitos programas brasileiros voltados à Educação Matemática. Esse dado mostra que é recente o interesse na temática - estudo conjunto da formação inicial e formação continuada do PEM nos anos iniciais de escolarização.

O professor do início da Educação Básica lida com diferentes áreas de ensino e investigações mais específicas sobre como se dá a integração entre formandos do Curso de Pedagogia e professores atuantes em sala de aula da Educação Infantil ou nos Anos 1 a 5 do Ensino Fundamental são muito relevantes. Estudos dessa natureza podem ter impacto no modo como o ensino da Matemática, em particular, é concebido e vivenciado pelo professor de anos iniciais de escolarização.

\section{Focos e objetivos dos estudos levantados}


Seguem os focos e autores das cinco dissertações, defendidas de 2008 a 2012, que tratam conjuntamente da formação inicial e continuada do PEM nos anos iniciais ${ }^{6}$ :

- Articulação entre a formação inicial na Pedagogia e a práxis pedagógica em Educação Matemática, dissertação de Mestrado Acadêmico de autoria de Eliene Dias, defendida em 2010 em programa da área de Ensino da Universidade de Brasília.

- Informática na formação inicial e continuada de professores que ensinam Matemática, dissertação de Mestrado Acadêmico de autoria de Maria de Lourdes Fernandes, defendida em 2009 em programa da área de Ensino da Universidade Cruzeiro do Sul.

- Investigando as práticas de ensinar e aprender matemática nos anos iniciais do Ensino Fundamental em um grupo do PIBID, dissertação de Mestrado Acadêmico de autoria de Eduardo Gallego, defendida em 2012 em programa da área de Educação da Universidade São Francisco.

- Desenvolvimento profissional de professores que ensinam Matemática: o método estudo e planejamento de lições nos contextos de escola e de ensino, dissertação de Mestrado Profissional de autoria de Patrícia Magalhães, defendida em 2008 em programa da área de Ensino da Pontifícia Universidade Católica de Minas Gerais.

- Ações colaborativas universidade - escola: o processo de formação de professores que ensinam Matemática nos anos iniciais, dissertação de Mestrado Acadêmico de autoria de Wagner Palanch, defendida em 2011 em programa da área de Ensino da Pontifícia Universidade Católica de São Paulo.

Observa-se que a colaboração entre pesquisadores de instituições de ensino superior e professores da Educação Básica está bem clara em três dos cinco estudos. Um desses estudos trata especificamente do PIBID (Programa Institucional de Bolsa de Iniciação à Docência), política pública na qual são oferecidas bolsas a estudantes de graduação que se dedicam a estágio $^{7}$ em escolas públicas, a professores das escolas nas quais ocorrem os estágios e a coordenadores de área (docentes universitários) que supervisionam os estágios.

Pesquisas anteriores, tais como a de Salles (2005), evidenciam que a colaboração universidade - escola é uma excelente alternativa, que contribui para a formação do professor. Isso também se aplica ao profissional que ensina Matemática nos anos iniciais do Ensino Fundamental - seja por proposta de uma instituição superior de ensino, seja a partir de uma política pública mais ampla como o PIBID - mas não se deve considerar como única ferramenta possível. Opções que partem da iniciativa da própria escola e são desenvolvidas

\footnotetext{
${ }^{6}$ Ressalta-se que as dissertações foram analisadas a partir dos seus textos completos, não apenas seus títulos ou resumos. Por isso, embora alguns dos títulos não explicitem, as cinco dissertações tratam de professores dos anos iniciais e conjuntamente da formação inicial e continuada.

7 Ressalta-se que o PIBID não se refere a estágio curricular, que é obrigatório a todos os graduandos de licenciaturas, no qual atuam em atividades típicas da docência. Já no PIBID, os estudantes selecionados discutem, elaboram e vivenciam atividades diferenciadas, a partir de uma dinâmica de cooperação entre os estudantes das licenciaturas, os professores das escolas e os docentes que supervisionam as ações.
} 
pelos profissionais da escola, também devem ser investigadas e discutidas.

Um dos cinco estudos focou mais especificamente na articulação entre a formação em Pedagogia e a prática de ensino de Matemática, e um outro estudo teve a tecnologia como foco de investigação na formação inicial e continuada de professores. Nenhum dos estudos tratou da educação a distância na formação de professores - que é um tema já consolidado quando se trata de formação nas áreas de Educação e de Ensino.

Quanto aos objetivos centrais e questões investigativas dos cinco estudos, tem-se:

- Investigar a articulação entre a formação inicial e a formação continuada no exercício da função docente, analisando, em particular, se a educação matemática vivenciada no curso de Pedagogia serve de modelo para práxis pedagógicas; no intuito de responder à seguinte pergunta investigativa: Como as vivências escolares e acadêmicas contribuem para a construção e consolidação de conceitos e saberes matemáticos? (Dias, 2010).

- Analisar o uso de tecnologias de informação e comunicação na formação inicial de professores e o reflexo desse uso em suas práticas pedagógicas; questionando como os professores que ensinam Matemática nos anos iniciais e outros níveis de ensino fazem uso de computadores em sala de aula, e as contribuições de suas formações (inicial e continuada) nesse uso (Fernandes, 2009).

- Identificar as reflexões de professoras de anos iniciais sobre o processo de aprender a ensinar Matemática a partir de discussões em um grupo de parceria universidade escola; investigando as contribuições dessa parceria no ensino de Matemática nos anos iniciais (Gallego, 2012).

- Investigar as potencialidades do método Lesson Plan Study (Estudo e Planejamento de Lições) para promover o desenvolvimento profissional de professores em atuação (em formação continuada) e futuros professores (em formação inicial) que ensinam/ensinarão Matemática (Magalhães, 2008).

- Analisar apoios e contribuições que o professor que ensina Matemática e o futuro professor dessa disciplina recebem ao participarem de projeto de colaboração universidade-escola, e verificar aprendizagens decorrentes desse trabalho colaborativo; questionando-se elementos constitutivos do trabalho docente no processo de formação de professores que ensinam Matemática nos anos iniciais (Palanch, 2011).

Apesar de serem poucas as dissertações que trataram conjuntamente da formação inicial e da formação continuada do PEM nos anos iniciais de escolarização, observa-se nelas um leque variado de focos e objetivos de pesquisa. A análise desses estudos, portanto, nos permite verificar alguns aspectos da formação em Pedagogia que se articulam com a prática em sala de aula, tais como os referentes ao aprendizado matemático dos licenciandos e as possibilidades de ensino da Matemática nos anos iniciais do Ensino Fundamental. Também se pode observar aspectos positivos e limitações de parcerias de instituições de nível superior com a escola da Educação Básica; bem como se pode analisar especificidades de Zetetiké, Campinas, SP, v.25, n1, jan./abr.2017, p.94-134 
determinadas propostas de formação - sejam métodos particulares de estudo e planejamento de ensino, sejam propostas de uso de recursos tecnológicos.

Uma observação relevante é a de que esses cinco estudos investigam a formação e atuação de professores no ensino de Matemática, de um modo geral, e não têm foco na discussão de conteúdos matemáticos específicos. Outro possível caminho de investigação, referente à articulação da formação inicial com a continuada, pode envolver a pesquisa de conteúdos matemáticos específicos, observando se a articulação é mais ou menos fortalecida dependendo do(s) conceito(s) discutido(s).

\section{Contextos das pesquisas analisadas}

Assim como os cinco estudos aqui descritos e analisados tiveram focos de pesquisa diferenciados, embora todos tratem da formação inicial e da formação continuada, os contextos de pesquisa também foram bem variados, evidenciado como pode ser rico esse campo de investigação e como o foco de pesquisa pode mudar a partir do contexto da investigação.

Analisar ementas e planos de curso, em particular dos componentes relacionados ao ensino, de maneira geral, e do ensino da Matemática, em particular, (tais como as disciplinas: Educação Matemática, Projetos de Prática Docente e Trabalho de Conclusão de Curso) e observar aulas de professoras que cursaram os referidos componentes curriculares, foi um dos contextos escolhidos para se observar relações entre a formação inicial - vivenciada no Curso de Pedagogia - e a formação continuada - proporcionada a partir de vivências de práticas pedagógicas (Dias, 2010).

Embora seja um contexto de pesquisa válido, pode-se questionar se o que consta em ementas e planos de curso é o que de fato é vivenciado na formação inicial. Podem, assim, ser sugeridos outros possíveis contextos que articulem mais efetivamente formação inicial e continuada: o de levantar junto a professores o que estudaram em disciplinas de graduação e o que consideram terem sido as contribuições das suas formações iniciais em suas práticas, e as necessidades de formação continuada que sentem; ou o acompanhamento de aulas na graduação - em disciplinas pedagógicas relacionadas a conteúdos matemáticos, em particular - e a observação de aulas de Matemática dos respectivos graduandos, então professores. Entretanto, reconhece-se que esse último contexto só pode ser concretizado em algum formato de pesquisa de longo prazo.

O contexto que envolveu professores do Ensino Fundamental (de anos iniciais e de anos finais) e professores do Ensino Médio que se reuniam regularmente com grupo de docentes e discentes de Instituição Superior de Ensino (Fernandes, 2009); e aquele que envolveu um grupo de professores de uma escola pública com graduandos em Pedagogia de uma universidade particular (Magalhães, 2008); e, ainda, o grupo no qual participaram estudantes de Pedagogia, da Licenciatura em Matemática e professores de anos iniciais (Palanch, 2011); também se mostraram adequados para a investigação conjunta entre 
formação inicial e formação continuada de professores que ensinam Matemática em início de escolarização. Esses contextos possibilitam, de fato, investigar como estudantes de cursos de licenciatura, i.e. professores em formação inicial, podem se articular com professores em atuação e que se encontram em contínua formação, pois, como apontam Boavida e Ponte (2002), juntando pessoas com variadas experiências e perspectivas, mas com objetivos em comum, há maior possibilidade de reflexão e aprendizagens.

Um contexto como aquele inserido no PIBID, tal como o que envolveu professoras de anos iniciais de escola municipal, estudantes de Pedagogia e pesquisador universitário sendo os dois primeiros grupos não especialistas em Matemática, mas que compartilhavam os conhecimentos que possuíam sobre o ensino e a aprendizagem da disciplina - também possibilitou análise da relação entre formação em Pedagogia e a formação continuada de professores de início de escolarização (Gallego, 2012). Ressalta-se a amplitude do programa nacional PIBID, alcançando um grande grupo de professores - em formação e em atuação sob a orientação de docentes de instituições superiores de ensino. O contexto do PIBID, certamente, ainda será foco de futuros estudos que busquem articulações entre a formação inicial de graduandos em Pedagogia e professores que atuam nos primeiros anos da Educação Básica.

Como já apontado anteriormente, essa parece ser a proposta mais comum quando se trata de estudar conjuntamente a formação inicial e a continuada de professores: investigar contextos que envolvem professores e estudantes universitários em conjunto com professores que atuam na Educação Básica. Aspectos positivos de parcerias podem ser destacados, tais como as trocas entre pesquisadores universitários e os que atuam nas salas de aula do Ensino Fundamental e Ensino Médio - compartilhando resultados de investigações acadêmicas e descobertas da observação cotidiana dos espaços escolares. Entretanto, pode-se questionar se essa é praticamente a única forma de investigar articuladamente a formação inicial e a formação continuada de professores. Haveria outras formas, em particular a partir de contextos nos quais a escola e/ou os professores da mesma fossem os propositores de investigações de suas próprias práticas e outros realizariam pesquisa de observação externa e análise do vivenciado na escola?

\section{Apresentação e discussão dos principais resultados dos estudos analisados}

Os estudos analisados apontam que muitos professores de anos iniciais não se sentem seguros quanto aos processos de ensino de Matemática e afirmam que, de modo geral, o curso de formação inicial não ofereceu base suficiente para o trabalho com essa disciplina em sala de aula. Essa insegurança se reflete em alguns casos extremos nos quais os professores deixam de trabalhar a Matemática junto com seus alunos e pedem que os alunos respondam exercícios de Matemática em casa e apenas os corrigem em sala de aula (Dias, 2010).

Propostas de formação, principalmente as que buscam articular a formação inicial com a continuada, têm se mostrado eficientes em superar dificuldades dos professores com a Matemática e em torná-los mais seguros no ensino da mesma, entretanto, os estudos também Zetetiké, Campinas, SP, v.25, n1, jan./abr.2017, p.94-134 
têm apontado que há outros fatores que têm forte influência nos processos de ensino e de aprendizagem e que, mesmo com formações consolidadas de professores, é preciso enfrentálos. André (2009) aponta que grande parcela de responsabilidade do sucesso ou fracasso do ensino recai sobre políticas educacionais e gestão escolar e essas se refletem também nas condições de trabalho do professor.

A organização e a cultura de trabalho das escolas têm grande influência na formação contínua de professores e, em consequência, impactam fortemente o desenvolvimento profissional de professores. Assim, métodos de formação - como o de Estudo e Planejamento de Lições (Cavey \& Berenson, 2005) - podem favorecer o desenvolvimento profissional, mas outros fatores podem impedir avanços. Dessa forma, são apontados como impedimentos à formação contínua: falta de tempo disponível para estudo, para pesquisa de recursos didáticos, para investigações em sala de aula e para experimentação de novas abordagens de ensino; cultura de trabalho individualista que impede ações colaborativas entre os professores, tais como a troca de materiais de ensino e de experiências vivenciadas junto aos alunos; e falta de mobilização de todos os professores da escola, no intuito de modificar práticas escolares de ensino e aprendizagem de Matemática (Magalhães, 2008). Nessa mesma direção, Nacarato (2005) aponta que há muitas potencialidades no trabalho coletivo na escola para promoção do desenvolvimento do professor, mas também há conflitos, condições de trabalho e cultura escolar a serem enfrentados.

Apesar do contexto escolar mais amplo com suas influências diversas, os processos de formação aqui analisados têm apontado aspectos positivos que possibilitam a ampliação de conhecimentos matemáticos dos professores. Observamos, dentre os ganhos com os processos formativos, que o crescimento da compreensão da Matemática por parte dos professores leva-os ao aumento de habilidades de planejamento e ao desenvolvimento de melhores estratégias de ensino.

Quanto à formação específica referente a Tecnologias de Informática e Comunicação (TIC), verificou-se que grande parte de instituições de ensino superior contempla algum modo de uso dessas tecnologias. Entretanto, a maioria das instituições limita-se ao uso de TIC para consumo próprio do professor em formação ou voltado para linguagens de programação. Em experiências de formação continuada de professores de anos iniciais, pouco também se tem abordado o uso de novas tecnologias para o ensino (Fernandes, 2009).

Assim, esta pesquisa verifica que há um comprometimento com relação à formação dos professores para o uso em sala de aula de TIC, em particular as tecnologias voltadas para o ensino de Matemática. O que se previa, já há algum tempo, de que novos recursos tecnológicos seriam utilizados de maneira eficiente em processos de ensino e de aprendizagem da Matemática, está longe, portanto, de ser uma realidade nas salas de aula de anos iniciais e, em grande parte, isso é reflexo do despreparo do professor para o uso de novas TIC. Experiências de formação - envolvendo professores em formação inicial e em formação continuada - podem ser muito eficazes, desde que se estimule a curiosidade dos professores e que lhes dê segurança na experimentação de novos recursos de ensino. 
Possibilita-se, assim, que se diminua receios em errar - tanto no uso do computador, quanto em relação a questões matemáticas.

Os estudos analisados apontam que formações de professores - com uso de novas tecnologias ou com outras propostas de formação - precisam estimular novas percepções do que é importante no aprendizado matemático das crianças. Esses estudos mostram que processos reflexivos - sejam individuais, sejam coletivos - por parte dos professores, são indispensáveis para mudanças de perspectivas docentes. Como apontado por Jaworski (1993), a reflexão crítica é um passo necessário para o desenvolvimento profissional de professores, lembrando que mudanças só podem ocorrer por vontade própria - ninguém muda ninguém mas pode-se prover a estrutura que ajude outros a mudarem. Zeichner e Liston (1987) ressaltam que outros - formadores e colegas, sejam graduandos em formação inicial, sejam professores em atuação - são importantes para o processo reflexivo, seja por suporte mútuo, seja por questionamento ou por assumir o papel de ouvinte. Serrazina (1999) defende, ainda, que quando os professores refletem, eles sentem a necessidade de saber mais Matemática e se tornam mais confiantes em propor atividades diferentes em sala de aula, dando novos sentidos a suas práticas de ensino.

Espaços para discussão produzem reflexões e conhecimentos sobre a docência em Matemática e podem resultar no uso de novas abordagens metodológicas em sala de aula. Parcerias escola-universidade podem, assim, contribuir para maior desenvolvimento de conhecimentos matemáticos e pedagógicos, estimular ampla reflexão sobre o que seja ensinar Matemática e, em consequência, possibilitar mudanças de discurso e de ações nos processos de ensino (Gallego, 2012).

Quando em processos são envolvidos professores em formação inicial e os atuantes em sala de aula, que também se encontram em formação continuada, os participantes apontam como aspecto muito positivo a oportunidade de interagir com pessoas com status de formação diferenciados. Os alunos de graduação podem contribuir com novas ideias e os professores atuantes em sala trazem contribuições referentes ao cotidiano escolar e experiências bem-sucedidas no mesmo. O trabalho coletivo e colaborativo pode, dessa forma, possibilitar o pensar e o repensar sobre o que seja ser professor, em particular professor que ensina Matemática nos anos iniciais de escolarização (Palanch, 2011). Entretanto, este estudo e outros nos remetem à reflexão que a formação de grupos colaborativos nem sempre é viável quando se trata de formação em larga escala - como a voltada para uma rede inteira de ensino.

Aspectos positivos são evidenciados nos estudos pesquisados referentes a modos de se propor articulação entre formações iniciais e continuadas de estudantes de Pedagogia e de professores de anos iniciais do Ensino Fundamental. As trocas entre os que ainda não estão em atuação, mas possuem ideias inovadoras, e os que já atuam em sala de aula, e possuem experiências referentes à realidade escolar, se mostram bastante instigantes e frutíferas, como defendem Zeichner \& Liston (1987) ao ressaltarem o papel de outros em processos reflexivos. Essas trocas podem resultar em mudanças na forma como o ensino de Matemática 
nos anos iniciais é entendido e colocado em prática.

Este trabalho também chama a atenção sobre cuidados que se fazem necessários em propostas dessa natureza. Reflexões e mudanças de práticas são possibilitadas, desde que se dê a devida voz aos professores - referente a suas ideias e suas experiências - respeitando opiniões, mas também estimulando colaboração na busca de melhorias na qualidade do ensino e, consequentemente, avanços na aprendizagem dos alunos. Espaços de colaboração e aprendizagem mútua, podem transformar a prática em sala de aula, bem como propulsar desenvolvimento profissional, como também defende Nacarato (2005). Nesse sentido, também se faz necessário considerar aspectos mais amplos do exercício docente, tais como políticas públicas, gestão escolar e condições de trabalho dos professores (André, 2009).

A articulação formação inicial - formação continuada pode ser efetuada de modo que dê maior segurança aos professores quanto aos seus conhecimentos matemáticos e quanto a modos de ensino da Matemática, por intermédio de reflexões que os tornam mais confiantes na proposição de atividades inovadoras (Serrazina, 1999). Em particular, pela possibilidade de ricas trocas se mostrarem bem eficientes nos processos que envolvem professores em formação e os atuantes em sala de aula, propiciando, assim, novas práticas de ensino.

Trocas muito interessantes, como as observadas nos estudos analisados, podem resultar da interação entre graduandos (licenciandos em Pedagogia e em Matemática) e professores atuantes (nos anos iniciais ou nos anos finais do Ensino Fundamental e no Ensino Médio). Essa organização pode combater a histórica separação, apontada por Gatti (2010), entre os professores polivalentes da Educação Infantil e dos anos iniciais do Ensino Fundamental e os professores especialistas que atuam nos anos finais do Ensino Fundamental e no Ensino Médio. Isso pode auxiliar na valorização do professor polivalente - tanto em termos de reconhecimento social, quanto em relação a carreira e salários - e pode promover uma reestruturação de modos mais integradores de formação de professores que ensinam Matemática.

\section{Considerações finais e alguns questionamentos para estudos futuros}

Levantamentos como este registram a memória de pesquisas, de modo a se evitar dispersões ou repetição de estudos (Charlot, 2000). Resgates e análises de estudos anteriores em uma temática possibilitam, assim, avanços nas investigações e, consequentemente, impactos sociais positivos podem ser alcançados - tais como a melhoria na formação docente.

Espera-se, assim, que o presente texto possa, de alguma forma, servir de ponto de partida para a realização de novos estudos que levem em consideração a articulação entre a formação inicial e a formação continuada de professores que ensinam Matemática nos anos iniciais de escolarização. Assim como ocorre na área de Educação, segundo André (2009), aqui também foram observados poucos estudos em Educação Matemática que tratem dessa temática, apesar de crescimento em estudos sobre formação de professores. Portanto, deseja- 
se que o presente levantamento seja estímulo à produção de mais estudos, incluindo dissertações e teses, que tratem conjuntamente da formação inicial e formação continuada de professores que ensinam Matemática, em particular dos profissionais que atuam na Educação Infantil e nos anos iniciais do Ensino Fundamental.

Referente aos níveis de ensino, ressalta-se como a formação inicial e continuada de professores que ensinam na Educação Infantil ainda precisa ser mais investigada. Elia \& Mulligan (2016) observaram, no cenário internacional, crescimento no número de pesquisas voltadas a esse período de escolarização, e a mesma tendência também precisa se tornar realidade no Brasil. Estudos voltados à formação de professores que atuam na Educação Infantil igualmente aumentaram internacionalmente, embora não seja consenso qual Matemática deva ser abordada na Educação Infantil. No levantamento aqui realizado não se observou preocupação específica em investigar a formação de professores que atuam na Educação Infantil, nem quais conteúdos matemáticos possam ser foco de formação, o que indica a necessidade de mais estudos referentes a esse nível de ensino.

É desejo, também, que estudos na temática aqui abordada - formação inicial e continuada de professores de início de escolarização - sejam foco de investigação em diferentes regiões brasileiras, e que mais experiências exitosas de formação possam ser compartilhadas. Deseja-se que, nessas experiências, diversos atores do cenário educacional estudantes, professores, gestores - possam ser envolvidos, e que as mesmas se revertam em melhoria da qualidade de ensino na Educação Básica no nosso país.

Observou-se um modelo eficiente de pesquisa na área - que envolve docentes e discentes de instituições de ensino superior e profissionais das escolas - e processos nesse formato já podem ser considerados como experiências muito bem consolidadas. Questionase, entretanto, que outros formatos de investigação e de formação são possíveis, em particular, serão possíveis processos que tenham como ponto de partida a iniciativa das próprias escolas? Este poderia ser um caminho que suprisse as limitações que surgem a partir da criação de grupos colaborativos, os quais não têm alcance de grandes quantitativos de professores, como os pertencentes a uma inteira rede de ensino.

Um programa inicialmente proposto por equipe de instituição de ensino superior pode ter como um de seus objetivos o de fazer os professores das escolas se sentirem responsáveis pelos seus próprios desenvolvimentos profissionais. Ao invés de se buscar meramente ensinálos, pode-se ter como objetivo o de tornar professores em pesquisadores (como apontado por Cochran-Smith \& Lytle, 2009) e promover o desenvolvimento das escolas.

Nessa direção, Serrazina (2014) relata uma experiência de formação docente Programa de Formação Contínua em Matemática (PFCM), desenvolvido em Portugal - na qual se buscou criar dinâmicas colaborativas entre os professores de uma escola e também de agrupamento de escolas. Este pode ser um caminho que estimule os professores a se sentirem responsáveis pelos seus próprios desenvolvimentos profissionais.

Dentre as subtemáticas pouco pesquisadas ou ainda não investigadas, tem-se: políticas 
públicas que envolvem professores em formação inicial e os atuantes em sala de aula (tais como o PIBID, que ainda precisa ser mais investigado, e os Observatórios da Educação ${ }^{8}$, que também precisam ser foco de pesquisa referente aos anos iniciais de escolarização); a formação de formadores (professores de cursos superiores); Educação a Distância (EAD); bem como o uso de recursos tecnológicos da atualidade (calculadoras, softwares e aplicativos, dentre outros, que podem ter impactos muito positivos no aprendizado), contrariando o que havia sido previsto por André (2009) como alguns prováveis temas emergentes. Serão esses novos caminhos do futuro da formação - inicial e continuada - de professores? Pesquisas nessa direção valem a pena serem realizadas.

Um outro foco de investigação, como apontado por Zehetmeier e Krainer (2011), refere-se à sustentabilidade de programas de desenvolvimento profissional. Nesse sentido, são necessários mais estudos que objetivem verificar os efeitos, a longo prazo, de programas de formação docente - sejam os de iniciativa de políticas públicas, sejam os surgidos a partir de grupos colaborativos propostos por equipes de instituições de ensino superior, ou ainda, os que surjam por iniciativa das escolas.

Mais ainda se torna necessário o (re)pensar da formação de professores que ensinam Matemática nos anos iniciais do Ensino Fundamental. A qualidade dessa formação - inicial e continuada - e o preparo dos formadores desses professores são questões a serem mais estudadas e investigadas. Dessa forma, vem mais um questionamento, semelhante ao apontado por Gatti (2010), no sentido de perguntar se é melhor que se invista na qualificação de cursos de formação de licenciados - considerando projetos de curso bem estruturados, docentes-formadores bem preparados e boa infraestrutura, em termos de recursos indispensáveis à formação em tempos atuais - para que a formação continuada possa ser mais voltada para atualizações, aperfeiçoamentos e especializações, e não mera complementação de uma formação inicial precária.

Para finalizar, considerando o que foi observado nos estudos aqui discutidos, resta um questionamento final, que, apesar de parcialmente respondido pelas pesquisas já realizadas, ainda carece de mais investigações. Qual tem sido e pode vir a ser o papel de gestores de políticas públicas, de Instituições de Ensino Superior e das escolas de Educação Básica na formação de professores que ensinarão/ensinam Matemática nos primeiros anos de escolarização? Que muitas pesquisas busquem respostas a este e outros questionamentos aqui apontados.

\section{Referências}

8 Observatório da Educação é um programa resultante da parceria entre a Capes (Coordenação de Aperfeiçoamento de Pessoal de Nível Superior), o Inep (Instituto Nacional de Estudos e Pesquisas Educacionais Anísio Teixeira) e a Secadi (Secretaria de Educação Continuada, Alfabetização, Diversidade e Inclusão) instituído em 2006, com o objetivo de promover a articulação entre pós-graduações, licenciaturas e escolas de Educação Básica. 
DOI: http://dx.doi.org/10.20396/zet.v25il.8647804

André, M. (2009). A produção acadêmica sobre formação de professores: um estudo comparativo das dissertações e teses defendidas nos anos 1990 e 2000. Revista Brasileira de Pesquisa sobre Formação Docente, 1(1), 41-56. Disponível em: http://formacaodocente.autenticaeditora.com.br

Boavida, A.M. \& Ponte, J.P. (2002). Investigação Colaborativa: Potencialidades e problemas. In GTI - Grupo de Trabalho sobre Investigação (Org), Reflectir e investigar sobre a prática profissional (pp.43-55). Lisboa: APM.

Brasil. (2001). Parecer CNE/CP $n^{\circ}$ 09, de 08 de maio de 2001: Institui as diretrizes curriculares nacionais para a formação de professores da educação básica, em nível superior, curso de licenciatura, de graduação plena. Brasília, DF. Disponível em: portal.mec.gov.br/cne/arquivos/pdf/009.pdf

Cavey, L. \& Berenson, S. (2005). Learning to teach high school mathematics: Patterns of growth in understanding right triangle trigonometry during lesson plan study. Journal of Mathematical Behavior, 24(01), 171-190.

Charlot, B. (2000). Da relação com o saber: elementos para uma teoria. Porto Alegre: Artmed.

Cochran-Smith, M. \& Lytle, S. L. (2009). Inquiry as stance: practitioner research for the next generation. New York: Teacher College Press.

Elia, I. \& Mulligan, J. (2016, novembro 28). Abstract of TSG 1: Early childhood mathematics education (up to age7). Disponível em: http://www.icme13.org/topic_study_groups

Gatti, B. (2010). Formação de professores no Brasil: características e problemas. Educação e Sociedade, 31(113), 1355-1379.

Jaworski, B. (1993). The Professional Development of Teachers - the Potential of Critical Reflection. British Journal of In-Service Education, 19(32), 37-42.

Moreira, P. \& David, M. (2007). A formação matemática do professor: licenciatura e prática docente escolar. Belo Horizonte: Ed. Autêntica.

Nacarato, A. (2005). A escola como locus de formação e de aprendizagem: possibilidades e riscos de colaboração. In D. Fiorentini e A. Nacarato (Orgs.). Cultura, formação e desenvolvimento profissional de professores que ensinam Matemática (pp. 175- 195). São Paulo: Musa Editora.

Nóvoa, A. (1991). Profissão Professor. Porto: Porto Editora.

OECD (1998). Staying Ahead: In-Service Training and Teacher Professional Development. Paris: OECD Publishing.

Pimenta, S. (Org.) (2012). Saberes Pedagógicos e Atividade Docente. (8a. ed.). São Paulo: Cortez Editora. 
DOI: http://dx.doi.org/10.20396/zet.v25il.8647804

Roldão. M. C. (2007). A formação de professores como objecto de pesquisa - contributos para a construção do campo de estudo a partir de pesquisas portuguesas. Revista Eletrônica de Educação, 1 (1), 50-118. Disponível em http://www.reveduc.ufscar.br

Salles, S. (2005). Colaboração universidade-escola: contribuições para o desenvolvimento profissional de professores de Matemática. Dissertação (Mestrado) - Universidade Estadual Paulista. Disponível em: https://repositorio.unesp.br/bitstream/handle/11449/91005/salles_s_me_rcla.pdf?sequenc $\underline{\mathrm{e}=1 \& \text { isAllowed }=\mathrm{y}}$

Serrazina, L. (1999). Reflexão, Conhecimento e Práticas Lectivas em Matemática num Contexto de Reforma Curricular no $1^{\circ}$ Ciclo. Quadrante, 8(02), 139-167.

Serrazina, M. L. (2014). O Professor que Ensina Matemática e a sua Formação: uma experiência em Portugal. Educação \& Realidade, 39(4), 1051-1069. Disponível em: http://www.seer.ufrgs.br/index.php/educacaoerealidade/article/view/45902/31459

Tardif, M. (2014). Saberes Docentes e Formação Profissional. (17a. ed.). Petrópolis, RJ: Vozes.

Zehetmeier, S., \& Krainer, K. (2011). Ways of promoting the sustainability of mathematics teachers' professional development. ZDM-The International Journal on Mathematics, 43(6/7), 875-887. Disponível em: http://link.springer.com/article/10.1007/s11858-011-0358-x

Zeichner, K.M. \& Liston, D.P. (1987). Teaching student teachers to reflect. Harvard Educational Review, 57(1), 23-48.

\section{APÊNDICE 1: Relação das dissertações do corpus de análise deste estudo}

Dias, E. (2010). Articulação entre a formação inicial na Pedagogia e a práxis pedagógica em Educação Matemática. Dissertação de Mestrado. Brasília: Universidade de Brasília.

Fernandes, M. (2009). Informática na formação inicial e continuada de professores que ensinam Matemática. Dissertação de Mestrado. São Paulo: Universidade Cruzeiro do Sul.

Gallego, E. (2012). Investigando as práticas de ensinar e aprender Matemática nos anos iniciais do Ensino Fundamental em um grupo do PIBID. Dissertação de Mestrado. Itatiba: Universidade de São Francisco.

Magalhães, P. (2008). Desenvolvimento profissional de professores que ensinam Matemática: o método estudo e planejamento de lições nos contextos de escola e de ensino. Dissertação de Mestrado. Belo Horizonte: PUC-Minas Gerais. 
DOI: http://dx.doi.org/10.20396/zet.v25il.8647804

Palanch, W. (2011). Ações colaborativas universidade - escola: o processo de formação de professores que ensinam Matemática nos anos iniciais. Dissertação de Mestrado. São Paulo: PUC-São Paulo. 